\title{
A virtual reality game for cognitive impairment screening in elderly: a user perspective
}

\author{
Eva Dulau ${ }^{1,2}$, Chrisna R Botha-Ravyse ${ }^{3}$, Mika Luimula ${ }^{1}$, Panagiotis Markopoulos ${ }^{4}$ and Evangelos Markopoulos ${ }^{5,1}$ \\ ${ }^{1}$ Turku University of Applied Sciences, Finland \\ ${ }^{2}$ ParisTech, France \\ ${ }^{3}$ North-West University, PHASREC, South Africa \\ ${ }^{4}$ University of the Arts London, London College of Communication, United Kingdom \\ ${ }^{5}$ HULT International Business School, United Kingdom \\ eva.dulau@gmail.com; chrisna.botha@nwu.ac.za; mika.luimula@turkuamk.fi; p.markopoulos1@arts.ac.uk; \\ evangelos.markopoulos@faculty.hult.edu
}

\begin{abstract}
Today, there are 50 million people suffering from dementia worldwide, that is a new case every 3 seconds and more than 152 million cases expected in 2050. Aging related morbidity is a real social problem making screening a major challenge. Early diagnosis and management would improve the quality of life offered to the patient and those around him and reduce the economic and social consequences of dementia. The traditional paper-and-pencil approach does not sufficiently reflect the daily reality of the person and what they are able to accomplish. The lack of ecological validity is one of the main criticisms of this approach.
\end{abstract}

Keywords-Virtual reality, Dementia, Neuropsychological assessment, Rehabilitation tool, Cognitive screening

\section{INTRODUCTION}

For the past 20 years, technological advancements have been contributing towards consolidating neuropsychological works. Virtual reality (VR) allows a better investigation of the behaviour and cognition in elderly people. With the other advantages offered by virtual reality, it is becoming easier to understand, assess, and could stimulate cognitive functioning of elderly people. This article examines the clinical interests provided by virtual reality applications for the neuropsychological assessment of the elderly. Notably, it has highlighted the naturalistic dimension of VR based devices for a better capture of the effects of dementia, and, through the results obtained from old adults and patients with dementia using the A Day to Remember Test evaluating the memory of daily task.

Therapists have seized the possibilities of this new mode of interaction and have contributed to the development of virtual environments targeting diagnosis, therapy, rehabilitation, and evaluation. We chose to focus on neuropsychology. The theme, still little investigated, that has caught our attention is to detect dementia.

Researchers have developed tools for early detection of cognitive disorders linked to pathological aging [1], for several reasons. The impact of dementia is not only significant, but also represents substantial human costs to countries, societies, families and individuals. Thus, early diagnosis makes it possible to set up therapeutic interventions as early as possible [2], whether through medication [3] or neuropsychologically [4]. By delaying the disease, a framework is set up around the patient and his entourage [5] who may present a depressive state [6].

Dementia has significant social and economic implications. In 2018 , the total global societal cost of dementia was estimated to be US \$1 trillion. In addition, with the growing aging of the population, these numbers should increase further: the number of cases would exceed 152 million in 2050, according to the predictions. Thus, the severe socioeconomic consequences of dementia promise to progress rapidly in the years to come. In 2030, the estimated cost is twice as much as today (US \$2 trillion).

The neuropsychological evaluation serves several functions. In clinical practice, she builds a rehabilitation strategy and measures her effectiveness [7]. This diagnosis of cognitive abilities seeks, on the one hand, to specify the cognitive components altered (and spared) by the disease (language, executive functions, memory, attention...). On the other hand, to define and measure functional capacities, revealing the process of integration of the different cognitive components, as they are manifested in daily activities. Most of the time, this evaluation focuses on work skills, meal preparation or the use of means of transport; in short, it deals with cognitive activities rather than cognitive functions. At the present time, assessment methods are evolving profoundly with the major objective of detecting earlier cognitive disorders that predict a pathology. What are the interests of early detection of dementia? What tools are available and how can VR address the shortcomings presented by conventional tools?

About our previous studies in neurosciences: Our research group called Futuristic Interactive Technologies at Turku University of Applied Sciences has previous experiences working with neuroscientists and testing elderly people who has 
cognitive disorders. In [CogInfoCom 2016, Scandinavian Journal of Psych.] studies we have focused on driving inspection with the development of NeuroCar, a virtual evaluation tool for a simultaneous evaluation of driving acuity and spatial perceptual capacity. NeuroCar's driving environment was visualized in VR glasses which enabled an immersive driving feeling (Fig 1 ). The driver had to react on visual and auditory disturbances by pressing the buttons while driving. In a laboratory setting the technology determines the right-side perceptual bias in aging.

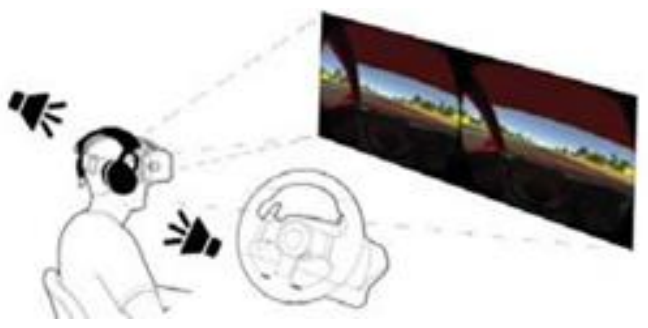

FIGURE 1. SYSTEM DESCRIPTION OF THE NEUROCAR SYSTEM [COGINFOCOM 2016].

The research we conducted in this study has two objectives. The first was to design an application in virtual reality by providing an immediate feedback on performance. The second was to identify the contributions of virtual reality by evaluating the usability by the commitment of the user. The creation and implementation of a neuropsychological evaluation through virtual reality has raised different issues: creating situations of familiar interaction that provoke engaging actions in patients; investigate the different facets of this commitment. The results of the patient study concluded that virtual reality neuropsychological evaluation is effective.

\section{THE TRADITIONAL NEUROPSYCHOLOGICAL APPROACH VERSUS THE ECOLOGICAL APPROACH}

Over the last twenty years, neuropsychology has seen the emergence of new techniques, complementary to conventional tools because they can bring a more integrative knowledge of human cognition. The purpose of this review is to highlight the benefits of one of these techniques, virtual reality (VR). Thus, the "paper-and-pencil" tasks are replaced by situations that are close to the activities of daily life. The contribution of this research concerns the adequacy of the virtual reality approach to diagnosis and therapy, and the consequent contributions.

\section{A. How evaluate dementia?}

These last years, many neuropsychological VR applications have been developed that offer simulations of daily activities that until now were carried out in the form of paper-and-pencil tests. Traditionally, in the neuropsychological clinic, the evaluation of episodic memory is carried out by learning tests of visual or verbal material, often lists of words. The traditional paper-and-pencil neuropsychological assessment allows to draw a person's cognitive profile in terms of strengths and difficulties. Many neuropsychological tests (MMSE, MoCA, FCSRT, TMTA and TMTB, WCST, verbal fluency) have very good psychometric qualities that make them indispensable tools for the diagnosis of dementia. Indeed, the traditional neuropsychological evaluation makes it difficult to predict the daily functioning of the individual [8] and therefore does not evaluate the disability of the subjects. Thus, the performances obtained by these "laboratory tests" do not give information on the real and daily functioning of the subject during complex activities.

Therefore, developing an evaluation tool at a time, ecological (in connection with the actual activities of the elderly person) to probe disability but also structural (identifying impaired cognitive functions / processes) would be a real breakthrough in the domain of neuropsychological diagnosis of pathological aging. This is precisely the first argument in favour of the use of VR as part of the neuropsychological evaluation, to study cognition in an ecological way.

\section{$B$. Use virtual reality : a real solution}

According to Fuchs et al. [9] "The purpose of virtual reality is to make possible a sensorimotor and cognitive activity for a person (or persons) in a digitally created artificial world, which can be imaginary, symbolic or a simulation of certain aspects of the real world.". This interaction in the virtual world puts the subject in a situation close to everyday life. The simulation of situations close to everyday life makes it possible to directly measure the disabilities and the handicap of the subjects, making it possible to detect cases of dementia [10] [11]. Similarly, VR has the advantage of creating an infinite number of natural and familiar virtual environments (e.g., city, store, classroom, home) and experimental tasks. The senses (vision, hearing, touch and proprioception) increase the immersion and realism of the virtual environment. It allows to save the data, to analyze them, to repeat the tasks, to manipulate the data of time, space, etc. Measurements with VR make it possible to accurately assess cognitive functioning through reliable indicators, eg response times, hesitations, eye fixations, types and numbers of errors. In summary, VR has many advantages in the context of neuropsychological use by performing more ecological, controlled, parametrized, standardized, safe and playful tasks

[12]

\section{VIRTUAL REALITY FOR THE ELDERLY}

Using VR with older people may seem complicated. But the VR technologies developed today bypass the problems formerly encountered with interfaces that are not adapted to the elderly person.

Indeed, twenty years ago, McGee et al. [13] identified four main constraints that explain the gap that now exists between older people and new technologies:

- technophobia (anxiety to use new products);

- the perceptual-motor status where aging is accompanied by a loss of visual and auditory skills as well as a reduction in 
motor performance [14] [15] that can hinder interactions with new technologies when they are poorly adapted;

- the evil of simulators. Indeed, disorders like the discomfort caused by motion sickness, which can occur during immersion in the virtual environment or after it and resulting from a conflict with received perceptual information. Symptoms may include nausea, eye strain, disorientation, perceptual-motor coordination problems, etc. [16];

- the complexity of using Human-Machine interfaces.

Today, the daily presence of the HMI has led the elderly to adapt quickly to this mode of interaction. They even ask for more technological assistance [17] (tablet, mobile phone...).

The RV, by its multisensory interactors makes it possible to circumvent the perceptual-motor incapacities of the person [18]. Note also that the 3D perception sought in RV applications is preserved until a very advanced age (over 90 years).

About simulator disorders, the literature reports that there is no difference between normal elderly people and elderly people with dementia concerning the presence of simulators [19]. First there are the technical solutions [20]. It is known that it is necessary to limit the lag time between the movements of the head and the images displayed less than 20 milliseconds, under pain of discomfort. The display frequency of the images must be at least $60 \mathrm{fps}$. Thus, it is necessary to limit sharp turns and information a screen, otherwise the look does not know where to fix. That is why it is recommended to move "by boxes" rather than linear trajectory. This amounts to a kind of teleportation, in which the player moves from one point to another, without moving, and thus disturbing his brain less. In addition to limiting movement, having a reference to the real world is crucial to give the player stable benchmarks. Considering these constraints related to the elderly user now provides interfaces adapted, simple and intuitive and therefore better accepted. These interfaces are considered by the users as useful (perceived interest) and usable (sense of efficiency in use) and therefore less anxiety for the person [21].

\section{IMMERSION LEVELS}

With regard to the different $3 \mathrm{D}$ interaction techniques, it is necessary to identify the levels of immersion of the individual in his task. According to Bowman \& McMahan study [22], it is better to offer a realistic experience to the user. Thus, it is more relevant to rely on a high level of sensory fidelity, through visual and auditory cues similar to those found in the real world. Based on their therapeutic, military and video game experiences, the virtual immersive environment experience requires a high level of immersion to increase the sense of presence. Similarly, the authors believe that the improvement in interaction performance is due to the proximity of the object to the user, its spatial understanding, i.e. its ability to perceive the 3D scene accurately to perform the task effectively. However, too much immersion can clutter the information. For users to agree to enter the virtual world, it is necessary to propose "credible scenarios from the point of view of the representativeness of the reference situations and from the point of view of pedagogical relevance in relation to the objectives of the training" [23]. Lourdeaux's thesis [24] shows that, in some VE experiments, instead of trying to reproduce reality as accurately as possible, it would be wise to focus on the most appropriate level of fidelity and realism. This is referred to as relevant sensory-motor immersion. Sometimes it is interesting to move away from realism to show hidden realities or to make abstract concepts understood. In 2016, an experiment [25] used conceptual visual feedback such as arrows and colours to indicate the action to be taken. Thus, the work focuses more on man's immersion in the task than on man's immersion in the virtual world. For the application experience, we thought of using a simple level of realism in the interaction that could correspond to all types of profiles (technophile, beginner, etc.).

\section{METHODS}

\section{A. Participants}

Studies show that if we screen dementia at the beginning of the disease, we have a chance to cure it, or at least to postpone the disease. That's why we chose to treat dementia only it at the early phase. The panel recruited for the experiment will be administered to 14 users who do not have Alzheimer's disease. We removed one participant's results because she had seen another user used the VR test.Participants are men and women aged 50-79 years old. Users come from three different places: two different retirement homes and the Turku university.

\section{B. VR Application}

A Day to Remember is a game design project that uses memory, audio and visual stimulation to help patients suffering from dementia with their everyday life. The project emulates the patients reality but at the same time gamifies it in order to become immersive and more enjoyable for the players. The game reports automatically a diversity of parameters on the behaviour of the user within the game, that are used to evaluate the cognitive skills. The ambition of the game is to bring motivation and fun in comparison to traditional paper-andpencil tests.

We created a navigation application sufficiently user-friendly to be satisfactorily used by subjects who are potentially cognitively impaired and may have limited experience with the virtual reality games. Users have passed 2 tests to detect dementia: the paper test and the virtual reality game test.

The health professionals have chosen the classic standardized screening MMSE test [26], a 30-point questionnaire that is used extensively in clinical and research settings to measure cognitive impairment. It is commonly used in medicine and allied health to screen for dementia.

Half of the users started with the paper test and the other with the virtual reality game to avoid for example a difference of fatigue. Then, they all have to answer a questionnaire with a tablet and give us more comments in oral (Fig.2). 


\begin{tabular}{|c|c|c|}
\hline Start user test & Second score \\
\hline Paper test MMSE & $\begin{array}{c}\text { ER application test } \\
\text { A Day to Remember }\end{array}$ & $\begin{array}{c}\text { Post-play } \\
\text { Questionnaire }\end{array}$ \\
\hline OUTSIDE VE & Interview \\
\hline VIRTUAL ENVIRONMENT & OUTSIDE VE \\
\hline
\end{tabular}

FIGURE 2. PROGRESS OF USER TESTS

A Day to Remember is a game-based test for the early assessment and training of mild cognitive disorders. It consists daily life tasks in a familiar 3D environment to assess different cognitive functions: executive function, language, memory (short and long-term perspective) and orientation (visuospatial). In Table 1, the scoreboard of the VR test.

TABLE II.

SCORING BY COGNITIVE FUNCTIONS

\begin{tabular}{|c|c|c|}
\hline Scale name & Scale & Tasks \\
\hline $\begin{array}{l}\text { Performing } \\
\text { familiar tasks } \\
\text { (executive } \\
\text { function) }\end{array}$ & 6 & $\begin{array}{l}\text { - Turn off alarm } \\
\text { - Open the fridge } \\
\text { - Take the lunch bag } \\
\text { - Close the fridge } \\
\text { - Take the wallet and the keys } \\
\text { - Take the safe's invitation }\end{array}$ \\
\hline $\begin{array}{l}\text { Short term } \\
\text { memory }\end{array}$ & 5 & $\begin{array}{l}\text { - Put the right PIN } \\
\text { - Task list not checked } \\
\text { - Memory game } \\
\text { - Q8: What was on the platform for } \\
\text { question 4? }\end{array}$ \\
\hline $\begin{array}{l}\text { Long term } \\
\text { memory }\end{array}$ & 5 & $\begin{array}{l}\text { Q2: What was the safe code number? } \\
\text {-Q3: Where did you find the wallet and } \\
\text { the keys? } \\
\text { - Q5: Which animal did you hear? } \\
\text { - Q6: Which animal did you NOT hear? } \\
\text { - Q7: What was the number of the bus } \\
\text { you took to the city center? }\end{array}$ \\
\hline Language & 4 & $\begin{array}{l}\text { - Animal sound } 1 \\
\text { - Animal sound } 2 \\
\text { - Animal sound spelling } \\
\text { - Q4: What is on the platform? (a bike) }\end{array}$ \\
\hline Orientation & 3 & $\begin{array}{l}\text { - Movement } \\
\text { - Stop the correct bus } \\
\text { - Q1: What day is it? }\end{array}$ \\
\hline
\end{tabular}

We removed two tasks. The first one is "Put your hand up to stop the bus" because the facilitator told the users how to stop the bus. The second task removed is "Close the entrance door" because every user forgot to do it. Probably because it is not instinctive in the virtual world to close a door or because the door was too far to close it. At the end, the score is on 23 in the VR game.

The user must sign the User Testing Informed Consent Form before the experiment to let them know that their performance within the VR environment are analysed. Before beginning the first task in the VR game, the facilitator performs one minute familiarization task in order to familiarize users with the environment and learn how to move around and interact with the objects.
The users need to know the story that they have been selected to participate in a TV show and before they have to do their everyday tasks. They know that their behaviour must be the same as in real life. For example, if they want to open the door, they must close it too. The user moves in the virtual world with the teleportation, a low-fatigue travel technique using only the trigger from controllers [27].

The game will have 3 main stages per path: The Room, the Path and the Questions.

\section{Step 1: Room Stage}

Once the game starts the player will "wake up" next to their bed in their room, he/she can see 3 daily tasks (Fig.3) before leaving the house. These tasks can be done in any order the player chooses.

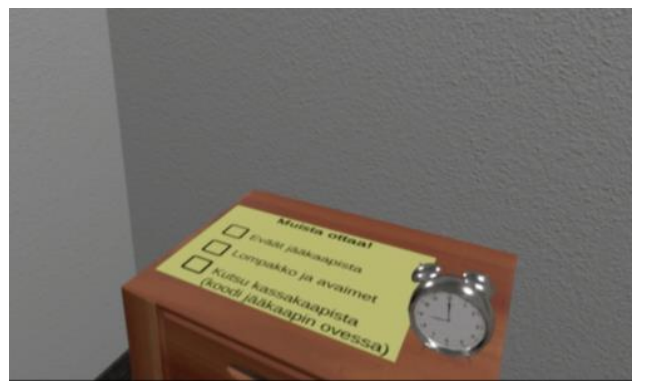

FIGURE 3. IN THE FIRST STAGE, THE PLAYER HAS TO PICK UP COLLECTIVES SUCH AS KEY OR WALLET.

\section{Step 2: Path stage}

During this stage, the player goes outside and explores the surrounding environment in the forest. The gamer hears animal scream and must choose between 4 animal names. Then, the user plays a memory game (Fig.4). The last task is raise their hand to stop the right bus.

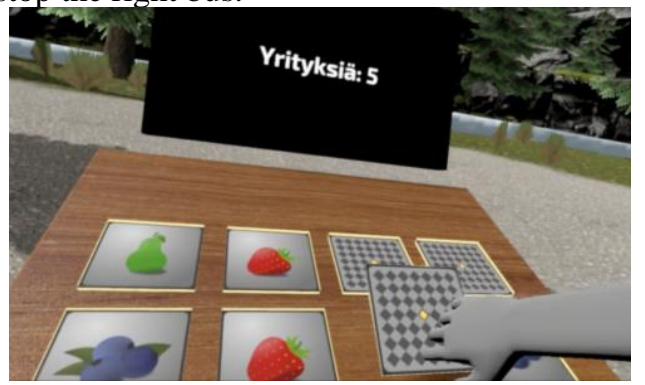

FIGURE 4. TRADITIONAL MEMORY GAME TESTING PLAYERS COGNITIVE SKILLS IN THE SECOND STAGE.

\section{E. Step 3: Question stage}

In the TV Show studio the player answers 8 questions (Fig.5) about the daily tasks and sees the final score.

In the current test, we have been using a simplified version of the game. In our vision, a part of interactions will be made with natural language understanding.

Our motivation to further develop this game concept towards more immersive and even natural user interface. 


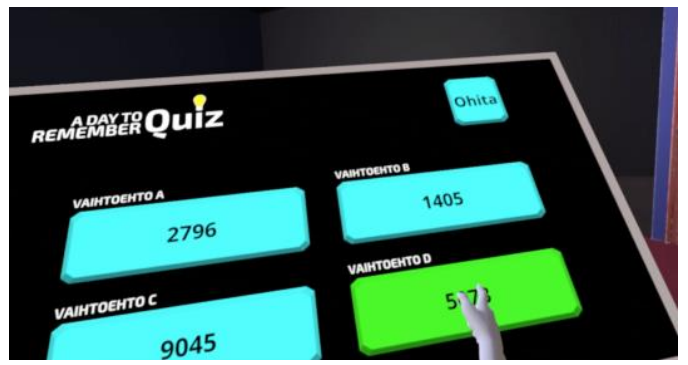

FIGURE 5. QUESTIONNAIRE ABOUT DAILY TASKS.

Before we should go further in this direction usability has to be evaluated especially because this game has been designed for older generations which are not experienced players either experienced of using virtual reality technologies. In the first version of this game where IBM Watson has already been used player's speech can be transcribed to written text and text in turn can be synthesized to natural sounding speech. This way player is able to conversate with the game using his or her own voice. Also chatbot has already been used to handle the dialog and to understand natural language [28].

\section{F. Measures}

In Table 2, the three stages of the experiment: the paper test, VR test and the questionnaire.

TABLE III. MEASURES

\begin{tabular}{|c|c|c|}
\hline Module & Scale & Scale name \\
\hline MMSE test & 30 & MMSE \\
\hline A Day to Remember test & 23 & ADTR \\
\hline Questionnaires & 5 & Questionnaire \\
\hline
\end{tabular}

The study made use of Likert-type scales, a unidimensional (measures a single trait) method of measuring responses. It is a common tool in social surveys or questionnaires. On a Likerttype scale question, respondents indicate their level of agreement or disagreement with a particular statement or question using an ordinal scale. Other qualitative data was collected by means of observation during play and option for further comments on the questionnaires. The data that were collected is presented in Table 3.

TABLE IV

QUESTIONNAIRE MODULES

\begin{tabular}{|c|c|c|l|}
\hline Module & $\begin{array}{c}\text { Items } \\
\boldsymbol{n} \boldsymbol{b}\end{array}$ & $\begin{array}{c}\text { Scale } \\
\text { name }\end{array}$ & \multicolumn{1}{|c|}{ Scale type } \\
\hline Subject & 3 & None & None \\
\hline Sickness & 16 & SSQ & $\begin{array}{l}\text { 4-point scale (none, slight, } \\
\text { moderate, severe) }\end{array}$ \\
\hline Usability & 10 & SUS & $\begin{array}{l}\text { 5-point Likert scale } \\
\text { (agree/disagree) }\end{array}$ \\
\hline Satisfaction & 6 & USEQ & $\begin{array}{l}\text { 5-point Likert scale (not at } \\
\text { all/very much) }\end{array}$ \\
\hline Presence & 14 & IPQ & 6-point scale \\
\hline
\end{tabular}

\section{G. Hypotheses}

H1: The VR-based application test is an appropriate device to screening dementia by offering immediate feedback on performance.

H2: The VR-based application is more engaging than paper test.

\section{RESULTS}

Statistical analysis was done using Google Forms and Excel. Descriptive statistics was done and reported as mean and SD. Seeing as this paper is a pilot and has a small sample size significance of results could not be calculated and therefore only means and SD were calculated in Table 4.

TABLE V.

DESCRIPTIVE STATISTICS

\begin{tabular}{|l|l|l|}
\hline Variable & $N$ & Mean $(\mathrm{SD}) * / \%$ \\
\hline Gender & $\begin{array}{l}\text { Male }(\mathrm{n}=6) \\
\text { Female }(\mathrm{n}=8)\end{array}$ & $\begin{array}{l}43 \% \text { male and } \\
57 \% \text { female }\end{array}$ \\
\hline $\begin{array}{l}\text { Level of } \\
\text { education }\end{array}$ & $\begin{array}{l}\text { Pensioners (n=9) } \\
\text { Self-employed persons }(\mathrm{n}=1) \\
\text { Upper-level employee }(\mathrm{n}=4)\end{array}$ & $64 \%$ pensioners \\
\hline Age & 14 & $66.6 \pm 8.36$ \\
\hline $\begin{array}{l}\text { Previous VR } \\
\text { use }\end{array}$ & $\begin{array}{l}\text { Yes }(\mathrm{n}=3) \\
\text { No }(\mathrm{n}=11)\end{array}$ & $\begin{array}{l}79 \% \text { no VR } \\
\text { experience }\end{array}$ \\
\hline
\end{tabular}

*Will only be reported if applicable

Five questionnaires modules have been assessed by therapeutic validity.

\section{A. Sickness}

Haptic effects (human-machine interactions) are sometimes difficult to produce [29] and there are sometimes sensory intolerances that can cause disorders (balance, seasickness, psychological intolerance). Knowing that all subjects were trying for the first time the VR headset, it was important to use the Simulator Sickness Questionnaire (SSQ). This questionnaire representing the overall severity of cybersickness experienced by the users in the game. In general, users responded that they did not feel any sickness after their experience, even if it was for all of them the first time they used a VR game. The general comfort $(26 \%)$, the fatigue $(23,8 \%)$ and the difficulty concentrating $(23,8 \%)$ are the only ones who can disturb. The number confirms that there is no difference between people aged 50 and 76 years old concerning the simulator sickness. Burdea and Coiffer (2003) provided a complete and detailed description of the recommended VR equipment.

\section{B. Usability}

System Usability Scale (SUS) score has a range of 0 to 100. Furthermore, measurements of usability have several different 
aspects: effectiveness (can users successfully achieve their objectives), efficiency (how much effort and resources are expended in achieving those objectives) and satisfaction (was the experience satisfactory). The positive result of our work evaluates the usability of this virtual environment for screening dementia, this indicates a possible useful application, but will have to be further tested on more participants.

In Table 5, the application rated a good level of usability with a score of $73 \pm 0,4$ (Score SUS = 29,2 x 2,5 = 73/100).

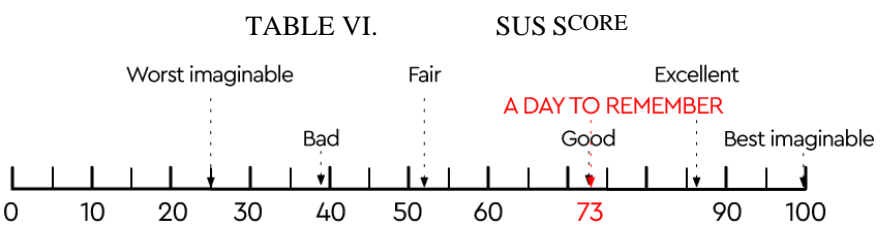

\section{Satisfaction}

Using VR technologies for cognitive assessment is still subject to further research. We would like to know if patient motivation and engagement improve the results. The User Satisfaction Evaluation Questionnaire (USEQ) is a questionnaire that is designed to properly evaluate the satisfaction of the user (which constitutes part of usability) in virtual assessment systems. Regarding the satisfaction measure, we asked the subjects 6 questions to determine whether the application allowed them to reach the goal, such as: enjoyment, successful using the application, able to control it, its understanding, the comfort and its usefulness. In Table 6, we calculated a mean value for overall satisfaction. We observed that the subjects were very enthusiastic during the use of the application. The mean for the satisfaction is $4,1 \pm 0,2$. However comfort scored lower $(3,8 \pm 0)$ because their glasses under the VR headset bothered the users. Indeed, the screen in the VR headset is so close that the convex of the glasses is the only way to see what is going on and this leads to a lot of moving your head up and down, Motivation is an important criterion because more users will be stimulated by using the application and they will be invested in the game. A Day to Remember works optimally to support screening dementia engaging the user.

TABLE VII. MEANS FOR THE SATISFACTION MODULE

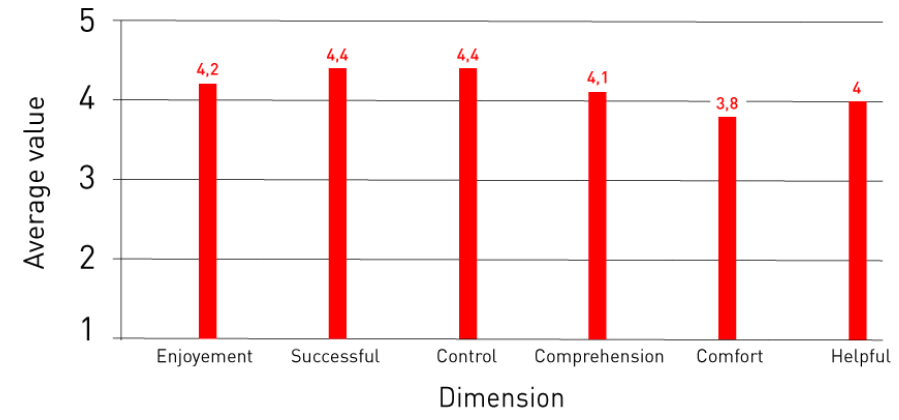

D. Presence

Lohse et al. (2013) have noted that well-designed video and VR games can increase time spent in rehabilitation thanks to the patient engagement and motivation. For the Presence module, the most relevant questionnaire is The Igroup Presence Questionnaire (IPQ) [30]. In order to measure presence, we used three subscales emerged from principal component analysis and can be regarded as independent factors:

- Spatial Presence (SP)- the sense of being physically present in the VE

- Involvement (INV) - measuring the attention devoted to the $\mathrm{VE}$ and the involvement experienced

- Experienced Realism (REA) - measuring the subjective experience of realism in the $\mathrm{VE}$

In Table 7 , the mean of SP $(4,5 \pm 0,38)$ and INV $(3,4 \pm 0,6)$ allow greater enjoyment of the application. The mean of REA is 4 $(3,5 \pm 1,07)$, it's enough to feel present in the game. Indeed, the question was put to them about the feeling of presence: "In the virtual environment I had a sense of "being there"'. The mean is $4,9 / 6 \pm 0$.

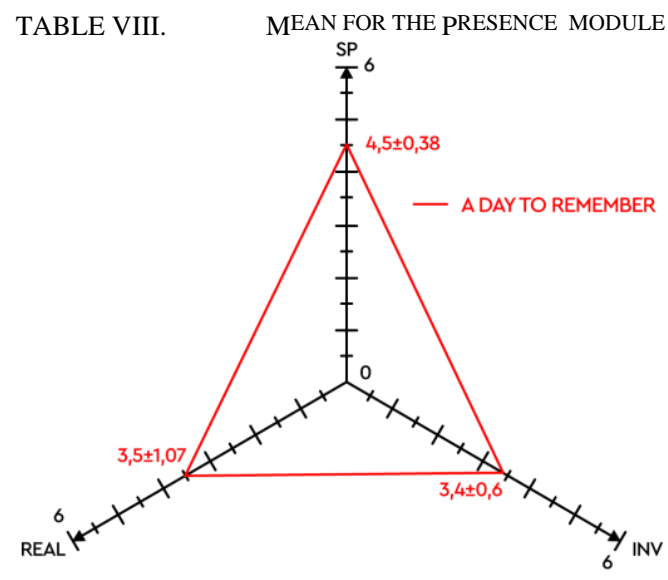

\section{E. Userfeedback}

Interview results showed that $75 \%$ of participants found the exercise simple and the application easy to use, which is good because we need that users feel reassured instead of stressed during the assessment. Whether the application is intuitive and user-friendly are essential points to motivate patients to use it. Finally, some of our users told us they felt more stressed before the screening test than after the VR game.

Finally, the challenge is to compare a cognitive evaluation made with A Day to Remember with those of a classic standardized screening test, a pencil-and-paper test.

We have a result of one user who is in early dementia (Score $=$ 20/30), which is also the worst score for the VR test (Score = 22/30). Two other users have a score of 25 for the MMSE test and 27 and 25 for the VR test. If we had more users, we could hypothesize that for the game VR, as for the MMSE test, it takes a score below 25 to confirm dementia at its early stage. In Table 8, we calculated a mean value for the paper test and the VR test. We reported the ratings of the VR game on 30 .

TABLE IX SCORES OF PAPER AND VR TESTS

\begin{tabular}{|l|l|l|l|}
\hline Age & N & Paper test (/30) & VR test (/30) \\
\hline
\end{tabular}




\begin{tabular}{|l|l|l|l|}
\hline 50 to 59 & 3 & $28,3 \pm 0.47$ & $29.1 \pm 0.6$ \\
\hline 60 to 69 & 4 & $26.75 \pm 1.4$ & $27.7 \pm 1.4$ \\
\hline 70 to 79 & 7 & $26.7 \pm 3.1$ & $26.5 \pm 2.28$ \\
\hline All ages & 14 & $27.1 \pm 2,4$ & $27.39 \pm 2.09$ \\
\hline
\end{tabular}

We can see that the younger people are the more their VR results are better. This can be explained that older people are more familiar with traditional tests and have more difficulty handling technology. In general, older people took longer to complete tasks. Elderly people over 70 years old take twice as long to walk through the house and finish the memory game. Similarly, they would check twice the list of tasks than users under 70 years.

Overall the subjects found the application useful and amusing while feeling immersed in this virtual world. The results of the virtual reality memory tests are a little better than the paper tests (0.29). This may be due to the fact that the game motivates and stimulates memory. During interviews, we had several user feedback who were afraid of medical tests but the game helped them to relax and be more focused.

However, there are several other factors involved. First, the users are guided throughout the game. Similarly, at the third stage, during the questionnaire, they have a multiple-choice questionnaire while in the paper test they must give an answer directly. Also, there is no calculation test in the VR game that there is in the MMSE test. Finally, the subjective variable is the visual memory that differs from the auditory memory. And we know that around $65 \%$ of the world's population being visual learners which can help to better remember.

\section{GAMIFICATION AND COMMERCIALIZATION}

The introduction of modern and innovative methods, techniques and practices in the critical sectors of the society and the economy face resistance to change, hesitation and skepticism especially when introduced in the health sector where patients can get the feeling of being test subjects on early stage research.

An effective way to achieve high and discrete user engagement, is the integration of gamification into the overall process. Game mechanics that reward the patients for their participation, achievements, patience, responsiveness and contribution, integrated in a pleasant environment under a gamified scenario of actions, stages and tasks, can effectively impact patient's engagement and deliver better and more accurate results.

Besides the user engagement, gamified approaches can also reach significant pedagogical targets, create social groups, and develop communities under the game challenges on individual or collective base.

VR is highly and closely related with the discipline of games design and the gaming industry. This link needs and must be utilized to health-related applications and technologies into fun, discrete and engaging experiences. VR related games are very immersive, live, interactive, offering much space for creativity, innovation and areas of application.
Gamification, though serious games, can turn innovative solutions, methods and approaches into successful commercial initiatives, projects, products or services. An effective game that assures user engagement and satisfaction can be utilized under various direct and indirect game monetization techniques that can vary from time to use, subscriptions, result analysis, data analytics and other data and metadata forms of processing. A Day to Remember matches all the requirements and conditions for its evolution into a serious game. Today the first game designs have been completed as well as the preliminary business plans.

\section{VIII.CONCLUSION AND FUTURE WORK}

This study does not compare these results with conventional neuropsychological evaluations, but it concludes that low-cost VR applications are good clinical tools which, in this case, make it possible to identify people whose cognitive abilities are impaired.

VR seems to keep its promises in terms of sensitivity of measures and identification of cognitive disorders. VR may have superior ecological validity compared to traditional pencil-and-paper neuropsychological tests for cognitive assessment because VR can simulate environments and objects that resemble patients' daily routines.

A Day to Remember test had good correlations between test scores and those of standard tests. But we recognize the lack of precision of the measures (do we guide too much the user?), The level of complexity of the course (how to make the game neither too hard nor too easy?), and the difference in ease of use technology by age. However, elderly people tolerate these interfaces very well when they are not familiar with the use of technology. In addition, the elderly testify a sense of satisfaction using this mode of evaluation.

A Day to Remember VR test is an appropriate device to screening dementia by offering immediate feedback on performance. This application is more engaging but will not replace the paper test. So, paper test and VR test are different but they both help to assess dementia. It is therefore important to keep in mind that an RV application that is too simple and too close to conventional tests does not improve the measurement quality. That's why they can be complementary. In the future, we will focus more on Natural Language Understanding (NLU) by using the latest AI technologies such as IBM Watson. As already mentioned, we have already first experiences of IBM Watson (Speech to Text, Text to Speech, and IBM Assistant). We are aware that the use of NLU systems in games can be engaging, enjoying and even decrease a sense of control, but in the same time more difficult to use and therefore decreasing the feel of story involvement [31]. In addition, an intensive use of dialogue systems utilizing NLU still has challenges because it is difficult to develop predictive dialogue systems where player is able to freely interact with the AI agent. "While I believe the complicated nature of this domain makes it incredibly difficult to come up with strong predictive models, further regression algorithms can also be applied to the data to get a better fit with more predictive power." [32] 
In the future, we will focus on studies to increase the immersiveness of the virtual 3D environment by using realistic spatial audio. In Pouru [33], first measurements of the realism of spatial audio and the subjective experience of immersion has been reported. This way we could create new cognitive tasks which would test player's memory based on auditory 3D signals.

Also new technologies, such as Varjo XR-1 glasses with eye tracking technology and human eye resolution will offer for us as researchers possibilities to create new cognitive tasks.

\section{ACKNOWLEDGMENT}

The authors would like to thank everyone who have participated in the game development. This work was supported by Business Finland, several companies, and Turku University of Applied Sciences. We also thank all the members of our lab for their help in conducting our experiments. Many thanks also to all the caregivers from Tammikoti who provided us with insightful comments and advice. Let's express our gratitude for Medical Doctor Joel Holmen from the university hospital.

\section{REFERENCES}

[1] Buracchio T, Kaye J. Early Diagnosis of Alzheimer's Disease and Mild Cognitive Impairment: Imaging, Biomarkers, and Technology. Generations. 2009;33(1):18-23

[2] Van der Linden, Martial. " Une approche cognitive du fonctionnement de la mémoire épisodique et de la mémoire autobiographique », Cliniques méditerranéennes, vol. no 67, no. 1, 2003, pp. 53-66.

[3] Seow, D., \& Gauthier, S. (2007). Pharmacotherapy of Alzheimer's Disease. The Canadian Journal of Psychiatry, 52(10), 620-629.

[4] Van der Linden, M., \& Juillerat, A.-C. (2004). La revalidation neuropsychologique dans la maladie d'Alzheimer à un stade précoce : Principes, méthodes et perspectives. Revue Neurologique, 160, 64-70.

[5] Tête, Caroline, et Yvette Chazelle. « Bibliographie thématique », Jusqu'à la mort accompagner la vie, vol. 117, no. 2, 2014, pp. 109-117.

[6] Sands, Laura Prouty et al. "What explains differences between dementia patients' and their caregivers' ratings of patients' quality of life?" The American journal of geriatric psychiatry : official journal of the American Association for Geriatric Psychiatry 123 (2004): 272-80 .

[7] Le Gall, Didier, et Philippe Allain. « Applications des techniques de réalité virtuelle à la neuropsychologie clinique », Champ psychosomatique, vol. no 22 , no. 2, 2001, pp. 25-38

[8] Sbordone, R. J. (2008). Ecological validity of neuropsychological testing: critical issues. Neuropsychol. Handbook 367:394.

[9] Fuchs P., Moreau G., Guitton P., Virtual Reality: Concepts and Technologies, July 2011, CRC Press.

[10] Evelyne Klinger. Apports de la réalité virtuelle à la prise en charge de troubles cognitifs et comportementaux. Autre [q-bio.OT]. Télécom ParisTech, 2006. Français. fftel-00161903f

[11] Werner P, Rabinowitz S, Klinger E, Korczyn AD, Josman N. Use of the virtual action planning supermarket for the diagnosis of mild cognitive impairment. Dement Geriatr Cogn Disord 2008;27:301-9.

[12] Rizzo, A.A., Schultheis, M.T., Kerns, K., et al.: Analysis of assets for virtual reality applications in neuropsychology. Neuropsychol. Rehabil. 14, 207-239 (2004)

[13] J.S. McGee, C. van der Zaag, J.G. Buckwalter, M. Thiebaux, A. Van Rooyen, U. Neumann, D. Sisemore, and A.A. Rizzo.CyberPsychology \& Behavior.Jun 2000
[14] Cavanaugh, J. C. (1997). Adult development and aging (3rd ed.) Pacific Grove, CA: Brooks/Cole.

[15] Whitbourne, S. K. (1998). Physical changes in the aging individual Clinical implications. In I. H. Nordhus, G. R. VandenBos, S. Berg, \& P Fromholt (Eds.), Clinical geropsychology (pp. 79-108). Washington, DC, US: American Psychological Association.

[16] Kennedy, Robert S. et al. "Profile Analysis of Simulator Sickness Symptoms: Application to Virtual Environment Systems." Presence: Teleoperators \& Virtual Environments 1 (1992): 295-301.

[17] Iancu, I.; Iancu, B. Elderly in the Digital Era. Theoretical Perspectives on Assistive Technologies. Technologies 2017, 5, 60.

[18] Wright WG. Using virtual reality to augment perception, enhance sensorimotor adaptation, and change our minds. Front Syst Neurosci. 2014;8:56. Published 2014 Apr 8. doi:10.3389/fnsys.2014.00056

[19] Flynn, D., van Schaik, P., Blackman, T., Femcott, C., Hobbs, B., \& Calderon, C. (2003). Developing a Virtual Reality-Based Methodology for People with Dementia: A Feasibility Study. CyberPsychology and Behavior, 6(6), 591-611.

[20] Andras Kemeny, Paul George, Frédéric Merienne, Florent Colombet. New VR Navigation Techniques to Reduce Cybersickness. The Engineering Reality of Virtual Reality, Jan 2017, San Francisco, United States. pp.48-53.

[21] Czaja, S. J., Charness, N., Fisk, A. D., Hertzog, C., Nair, S. N., Rogers, W. A., \& Sharit, J. (2006). Factors predicting the use of technology: Findings from the Center for Research and Education on Aging and Technology Enhancement (CREATE). Psychology and Aging, 21(2), 333-352.

[22] Doug A Bowman and Ryan P McMahan. 2007. Virtual reality : how much immersion is enough? Computer 40, 7 (2007).

[23] Michel Crampes and Gérard Saussac. 1999. Facteurs qualité et composantes de scénario pour la conception de simulateurs pédagogiques à vocation comportementale. Sciences et Technologies de l'Information et de la Communication pour l'Éducation et la Formation 6, 1 (1999), 11-36.

[24] Domitile Lourdeaux. Réalité virtuelle et formation : conception d'environnements virtuels pédagogiques. Interface homme-machine [cs.HC] École Nationale Supérieure des Mines de Paris, 2001. Français. fftel-00006475f [25] Gwendal Le Moulec, Ferran Argelaguet, Anatole Lécuyer, and Valérie Gouranton. 2016. Take-over control paradigms in collaborative virtual environments for training. In Proceedings of the 22nd ACM Conference on Virtual Reality Software and Technology. ACM, 65-68.

[26] Folstein, M. F., Folstein, S. E., \& McHugh, P. R. (1975). "Minimental state". A practical method for grading the cognitive state of patients for the clinician. Journal of Psychiatric Research, 12(3), 189-198.

[27] Sarupuri, Bhuvaneswari et al. "Trigger Walking: A low-fatigue travel technique for immersive virtual reality." 2017 IEEE Symposium on 3D User Interfaces (3DUI) (2017): 227-228.

[28] Lintuaho, 2019. IBM Watson in a game project. http://urn.fi/URN:NBN:fi:amk-2019061817317

[29] Mellet-Huart D. La réalité virtuelle: un média pour apprendre. Cinquième colloque hypermédias et apprentissages 2001;331-8.

[30] Valentin Schwind, Pascal Knierim, Nico Haas, and Niels Henze. 2019. Using Presence Questionnaires in Virtual Reality. In Proceedings of the 2019 CHI Conference on Human Factors in Computing Systems (CHI '19). ACM, New York, NY, USA, Paper 360, 12 pages

[31] Serdar Sali, Noah Wardrip-Fruin, Steven Dow, Michael Mateas, Sri Kurniawan, Aaron A. Reed, and Ronald Liu. 2010. Playing with words: from intuition to evaluation of game dialogue interfaces. In Proceedings of the Fifth International Conference on the Foundations of Digital Games (FDG '10). ACM, New York, NY, USA, 179-186.

[32] Sali, Serdar et al. "Playing with words: from intuition to evaluation of game dialogue interfaces." FDG (2010).

[33] Pouru, Lasse (2019). The Parameters of Realistic Spatial Audio : An Experiment with Directivity and Immersion. http://www.theseus.fi/handle/10024/226681 